УДК 633.88:631.8:631.55:581.192

\title{
К ВОПРОСУ НАКОПЛЕНИЯ НИТРАТОВ В ТРАВЕ ЭХИНАЦЕИ ПУРПУРНОЙ СВЕЖЕЙ И ЕЕ СОКЕ ПРИ ИСПОЛЬЗОВАНИИ МАКРО- И МИКРОЭЛЕМЕНТОВ
}

(ㄱ В.Б. Загуменников, А.В. Молчанова ${ }^{2}$, Е.Ю. Бабаева ${ }^{3 *}$, А.Л. Петрова

'Всероссийский научно-исследовательский институт лекарственных
и ароматических растений РАСХН, ул. Грина, 7, Москва, 117216 (Россия)
${ }^{2}$ Всероссийский научно-исследовательский институт селекции и
семеноводства овощных культур, п/о Лесной Городок Одинцовского района
Московской области, 143080 (Россия), е-таil: vovka_ks@rambler.ru
${ }^{3}$ Российский университет дружбы народов, ул. Миклухо-Маклая, 6, Москва,
117198 (Россия), e-mail: babaevaelena@mail.ru

Впервые проанализировано содержание нитратов в траве эхинацеи пурпурной свежей, ее структурных элементах и соке за 2 года исследований в зависимости от возраста растений, некорневых подкормок растворами, содержащими $\mathrm{N}, \mathrm{Co}, \mathrm{Fe}, \mathrm{B}, \mathrm{Si}$, и года проведения опыта.

Ключевые слова: Echinacea purpurea, трава свежая, сок, нитраты, макро-и микроэлементы.

\section{Введение}

Исследования последних лет показывают, что своими целебными свойствами препараты из лекарственного растительного сырья (ЛРС) обязаны оптимальному соотношению и гармоничному воздействию комплекса содержащихся в них биологически активных веществ (БАВ). Эхинацею пурпурную Echinacea purpurea (L.) Moench., (Asteraceae) культивируют США и интродуцировали во многие страны мира с целью получения препаратов иммуностимулирующего действия из травы высушенной и свежей, а также корневищ с корнями. Наименее изученным сырьем является трава свежая. Нормативный документ на нее появился только в 2008 г. [1]. Препараты из этого вида сырья - сок с добавлением спирта в качестве консерванта, а также высушенный сок с последующим таблетированием.

При использовании свежего ЛРС важно иметь информацию о содержащихся в нем нитратах. Возникают вопросы экологических последствий аккумуляции нитратов в ЛРС и их влияния на здоровье человека. Отрицательное влияние нитратов, особенно их восстановленной формы - нитритов, на организм человека связано с развитием метгемоглобинемии $[2,3]$. При нормальных условиях гемоглобин крови (Нb) выступает в роли акцептора $\mathrm{O}_{2}$. Патогенез заболевания следующий: Нb в условиях нитратного прессинга об-

Загуменников Валерий Борисович - ведущий научный сотрудник лаборатории агротехники и агрохимии

Молчанова Анна Владимировна - научный сотрудник лаборатории агрохимических средств, e-mail: vovka_ks@rambler.ru

Бабаева Елена Юрьевна - доцент, кандидат биологических наук, e-mail: babaevaelena@mail.ru Петрова Анна Леонидовна - провизор, интерн кафедры фармацевтической и токсикологической химии, e-mail: petryshka@yandex.ru разует комплексы $\mathrm{Hb}-\mathrm{NO}_{2}$ и $\mathrm{Hb}-\mathrm{NO}$, выпадая из кислородного обмена организма [4, 5]. Допустимая безопасная суточная доза нитратов для человека 5 мг на 1 кг массы. Допустимая среднесуточная доза нитратов в разных странах колеблется от 50 до 300 мг/чел. в сутки [6]. Для ЛРС, используемого в свежем виде, сведения о содержании нитратов фрагментарны [7]. В частности, они отсутствуют для травы эхинацеи пурпурной свежей и получаемого из нее сока.

\footnotetext{
* Автор, с которым следует вести переписку.
} 
Для получения урожая сырья культивируемых растений с высоким содержанием БАВ вносят макро- и микроудобрения. Одним из наиболее целесообразных способов внесения микроудобрений являются некорневые подкормки [8].

Азот играет главнейшую роль в жизни не только растений, но и всего органического мира. Карбамид - лучшая среди азотных удобрений форма для некорневых подкормок. Может поглощаться клетками листьев в виде целой молекулы и усваиваться растениями путем прямого вовлечения в цикл превращений азотистых веществ [9]. В основе положительного действия ионов кобальта на продуктивность растений лежит его влияние на формирование и функционирование фотосинтетического аппарата. Для некорневых подкормок применяют растворы $\mathrm{CoSO}_{4}[9,10]$. Бор оказывает существенное влияние на процесс фотосинтеза. Возрастает его интенсивность в листьях и отток углеводов к корням и репродуктивным органам в период формирования семян и накопления в них крахмала. В качестве борного удобрения при некорневой подкормке чаще всего используется $\mathrm{H}_{3} \mathrm{BO}_{3}$ [9]. Наиболее чувствительными к дефициту железа являются многолетние культуры. Феровит представляет собой раствор хелатного железа. Железо является важным катализатором образования хлорофилла, участвующего в процессах фотосинтеза и дыхания [11]. Силиплант - это микроудобрение, основным элементом которого является кремний. Он способствует повышению устойчивости растений к негативным факторам внешней среды, в том числе к возбудителям заболеваний, вредителям и сорным растениям [9].

Поскольку почвы Московской области обеднены усвояемыми формами многих элементов, в том числе вышеназванных, представляется перспективным проанализировать результаты внесения соединений кобальта, бора, железа и кремния в виде некорневых подкормок на эхинацее пурпурной, выращиваемой для получения свежей травы. Влияние макро- и микроэлементов на накопление нитратов в траве эхинацеи пурпурной свежей и продуктах ее переработки не изучено.

Цель работы - изучить накопление нитратов в траве эхинацеи пурпурной свежей по структуре (отдельно в листьях, стеблях, соцветиях и их зачатках), а также соке в зависимости от возраста растений, года проведения опыта и некорневой подкормки микроудобрениями и азотом.

\section{Экспериментальная часть}

В работе использовалось сырье «эхинацеи пурпурной трава свежая», полученное от растений $2,3,4$, 5 и 7 годов вегетации (г. в.), заготовленное в фазу массового цветения на территории опытного севооборота ВИЛАР в 2009-2010 гг. Посевной материал (семянки) репродукции ВИЛАР. Исследовали также сок, полученный из травы эхинацеи свежей. Сбор свежей травы, получение сока и определение в них нитратов проводили в течение одного дня. Сок отжимали на ручной соковыжималке марки Healthy Juicer. Содержание нитратов определяли согласно ГОСТу 29270-95 ионометрическим методом [12]. Аналитическая повторность 3-кратная. Математическую обработку результатов проводили методом дисперсионного анализа [13]. В качестве основного удобрения использовали «Кемира - Свекловичное 6», содержащее комплекс макро- и микроэлементов, из расчета $\mathrm{N}_{80} \mathrm{P}_{60} \mathrm{~K}_{90}$. Для изучения влияния некорневой подкормки растений эхинацеи растворами $\mathrm{CO}\left(\mathrm{NH}_{2}\right)_{2}, \mathrm{CoSO}_{4}, \mathrm{H}_{3} \mathrm{BO}_{3}$, феровита, силипланта, а также совместных обработок указанными растворами на содержание в траве эхинацеи пурпурной свежей и соке нитратов был заложен полевой опыт по схеме:

1. Без обработки.

2. Обработка водой.

3. $2 \%$ раствор мочевины.

4. $0,1 \%$ раствор $\mathrm{CoSO}_{4}$.

5. $2 \%$ раствор мочевины $+0,1 \%$ раствор $\mathrm{CoSO}_{4}$.

6. $0,1 \%$ раствор $\mathrm{H}_{3} \mathrm{BO}_{3}$.
7. $2 \%$ раствор мочевины $+0,1 \%$ раствор $\mathrm{H}_{3} \mathrm{BO}_{3}$.

8. $0,2 \%$ раствор феровита.

9. $2 \%$ раствор мочевины $+0,2 \%$ раствор феровита.

10. $0,2 \%$ раствор силипланта.

11. $2 \%$ раствор мочевины $+0,2 \%$ раствор силипланта.

Для того, чтобы вычленить действие изучаемых соединений в водных растворах на накопление нитратов в ЛРС и соке, за контроль взяты два варианта: без обработки и вариант с внесением воды. Концентрации растворов веществ определены в предыдущих опытах [14]. Концентрация раствора $\mathrm{CoSO}_{4}$ дана по соли. Полевые опыты проводили на дерново-среднеподзолистой тяжелосуглинистой почве. Площадь делянки общая $27 \mathrm{~m}^{2}$, учетная 16,8 м², повторность 3-кратная. Растворы вносили с помощью ручного опрыскивателя из расчета 600 л/га в фазу бутонизации. Наступление фаз определяли согласно «Методике исследований при интродукции лекарственных растений» [15]. 


\section{Обсуждение результатов}

Многими исследователями отмечено, что наибольшая концентрация нитратов наблюдается в стеблях и черешках листьев независимо от вида растения [4]. Высокое содержание нитратов в стеблях растений различных видов является устойчивым признаком и связано с активным перераспределением в растительном организме нитрат-иона в сосудисто-волокнистые проводящие пучки и смежные с ними ткани [16]. Независимо от возраста растений эхинацеи пурпурной, от которых получено ЛРС в 2009 г., некорневых подкормок микроудобрениями и азотом, максимальное достоверное содержание нитратов наблюдали в стеблях (табл. 1), что подтверждает общую закономерность. В среднем по вариантам в соцветиях и их зачатках растений эхинацеи 2 и 3 гг. в. нитратов накапливалось 1,3-1,7 раза меньше, а в листьях их содержание было ниже в 4,7-6,4 раза по годам соответственно, чем в стеблях.

Некорневая подкормка эхинацеи растворами $\mathrm{CoSO}_{4}$ и феровита способствовала достоверному снижению содержания нитратов по сравнению с контролем в стеблях эхинацеи: для растений 2 г. в. оно составило 6\% в обоих вариантах. В стеблях растений 3 г. в. внесение всех микроэлементов, кроме раствора $\mathrm{H}_{3} \mathrm{BO}_{3}$ приводило к уменьшению уровня нитратов на 2-38\%.

Внесение растворов микроэлементов оказало существенное влияние на накопление нитратов в листьях эхинацеи. В листьях растений 2 г. в. уменьшение содержания нитратов отмечено при подкормке растворами $\mathrm{CoSO}_{4}$ и феровита на 27\%, а раствором силипланта - на $8 \%$ в сравнении с контрольным вариантом. Листья растений 3 г. в. при обработке растворами $\mathrm{CoSO}_{4}$ и феровита содержали нитратов меньше на 33 и $37 \%$ соответственно.

У соцветий растений 2 г. в. внесение раствора $\mathrm{CoSO}_{4}$ снижало содержание нитратов на $5 \%$ к контролю, а феровита - на 13\%. Некорневая подкормка растений 3 г. в. растворами $\mathrm{CoSO}_{4}$ и феровита приводила к снижению уровня нитратов в соцветиях и их зачатках на 14 и $15 \%$ соответственно.

Внесение в фазу бутонизации некорневой подкормки 2\% раствором карбамида в 2009 г. достоверно увеличивало накопление нитратов в структурных элементах травы эхинацеи по сравнению с вариантами без внесения азота, независимо от внесения микроэлементов.

Для стеблей растений 3 г. в. по сравнению с таковыми 2 г. в. превышение составило 1,4 раза, для листьев $6 \%$, для соцветий и их зачатков $8 \%$. Совместная некорневая подкормка растений эхинацеи растворами карбамида и микроэлементов способствовала еще более значительному росту содержания нитратов в элементах травы в зависимости от возраста по отношению к вариантам без карбамида. Так, в стеблях растений 3 г. в. накапливалось нитратов в 1,6 раза больше, чем в стеблях растений 2 г. в., в листьях - в 1,8 раза, а в соцветиях и их зачатках - в 1,9 раза.

Из анализа данных логично вытекает, что стебли растений 2 и 3 гг. в. накапливали существенно (в полтора - два раза) больше нитратов как при внесении только одного раствора карбамида, так и при сочетании его с микроэлементами, чем варианты без внесения карбамида. При этом стебли растений 2 г. в. содержали нитратов достоверно меньше, чем таковые 3 г. в. В наименьшей степени увеличивалось содержание нитратов в стеблях по сравнению с контролем при обработке растений 2 г. в. растворами карбамида и феровита - на $3 \%$. По другим вариантам в стеблях растений 2 г. в. превышение к контрольному варианту составило 44-74\%.

Однако если накопление нитратов в стеблях растений эхинацеи 2 и 3 гг. в. при внесении растворов карбамида и микроэлементов подчинялось единообразной закономерности, то их содержание в листьях, а также соцветиях и их зачатках по годам различалось. В листьях, соцветиях и их зачатках растений 2 г. в. внесение раствора карбамида, как отдельно, так и в сочетании с растворами микроэлементов, приводило к снижению содержания нитратов, что можно объяснить интенсивным ростом и переходом к матурной фазе онтогенеза. Эти процессы стимулируются дополнительным внесением азота, с одной стороны, и требуют расхода еще большего его количества, с другой стороны. Наиболее сильное уменьшение содержания нитратов в листьях растений 2 г.в. в сравнении с вариантами без карбамида отмечено в варианте с обработкой растений эхинацеи раствором феровита - на 46\%. В других вариантах убыль нитратов составляла $25-30 \%$. В соцветиях и их зачатках растений 2 г.в. содержание нитратов в наибольшей степени уменьшалось при совместной некорневой подкормке растворами карбамида и $\mathrm{CoSO}_{4}$ (на $39 \%$ ).

В листьях, а также соцветиях и их зачатках растений эхинацеи 3 г.в. закономерность накопления нитратов была такой же, как и для стеблей - с внесением карбамида отдельно или в сочетании с микроэлементами содержание нитратов по сравнению с контролем возрастало: в листьях на 2-36\%, в соцветиях и их зачатках на $10-45 \%$. 
Концентрация нитратов в траве эхинацеи напрямую зависела от их содержания в структурных элементах. В траве растений 2 г. в. достоверное уменьшение содержания нитратов обеспечивали некорневые подкормки растворами $\mathrm{CoSO}_{4}$ и феровита (на 9 и 10\% соответственно). В траве растений 3 г. в. отмечены незначительные колебания уровня нитратов по отношению к контролю при внесении растворов феровита и $\mathrm{CoSO}_{4}$ - на 2-3\%. Варианты же, включающие обработку растений растворами силипланта и борной кислоты, увеличивали накопление нитратов в траве на 12-14\%.

Комплексные некорневые подкормки эхинацеи, включающие растворы карбамида и микроэлементов, позволили выявить достоверное снижение уровня изучаемых ксенобиотиков при внесении растворов $\mathrm{CoSO}_{4}$ и феровита для травы растений 2 г. в. Уменьшение их количества составило 12 и 35\% соответственно. В траве растений 3 г. в. содержание нитратов при комплексных подкормках растворами карбамида, $\mathrm{CoSO}_{4}$ и феровита почти не менялось по сравнению с вариантами без карбамида. В то же время внесение на фоне раствора карбамида растворов $\mathrm{H}_{3} \mathrm{BO}_{3}$ и силипланта приводило к увеличению концентрации нитратов в траве на 9-29\%. Трава растений 3 г. в. как в вариантах без карбамида, так и в вариантах с применением комплексной подкормки содержала достоверно больше нитратов по сравнению с травой, полученной от растений 2 г. в.

Основную массу сока выделяют из листьев как наиболее оводненного элемента травы эхинацеи пурпурной свежей. В них нитраты в наибольшем количестве содержатся в черешке и крупных жилках. Стебли, корзинки и их зачатки дают несколько меньше сока, но содержание нитратов в них выше, чем в листьях, так как там больше проводящих тканей.

В итоге, сок из травы свежей характеризовался наибольшим накоплением нитратов по сравнению со структурными элементами травы свежей и ЛРС в целом (рис. 1) вследствие того, что там сконцентрированы все водорастворимые соединения (включая нитраты).

Правомерность этого заключения верна независимо от возраста растений, с которых срезана трава, и внесения подкормок растворами соединений с микроэлементами и азотом (рис. 2). Повышение концентрации нитратов в соке по сравнению с их содержанием в траве составило независимо от вариантов для растений 2 г. в. 35-43\%, а для растений 3 г. в. 38-46\%.

Таблица 1. Влияние некорневых подкормок на содержание нитратов в свежем сырье эхинацеи пурпурной 2 и 3 гг. вегетации 2009 г., мг/кг

\begin{tabular}{|c|c|c|c|c|c|}
\hline Вариант & $\begin{array}{l}2 \% \text { раствор } \\
\text { карбамида }\end{array}$ & Стебли & Листья & $\begin{array}{c}\text { Соцветия и их } \\
\text { зачатки }\end{array}$ & Трава \\
\hline \multirow[t]{3}{*}{ Без обработки } & \multirow{2}{*}{-} & $\underline{2029}$ & $\underline{509}$ & $\underline{1664}$ & $\underline{1443}$ \\
\hline & & 3412 & $\overline{548}$ & $\overline{1791}$ & $\overline{1467}$ \\
\hline & + & - & - & - & - \\
\hline \multirow[t]{4}{*}{ Вода } & \multirow{2}{*}{-} & 2023 & 507 & 1661 & 1439 \\
\hline & & 3410 & 546 & 1789 & 2164 \\
\hline & \multirow{2}{*}{+} & $\underline{3040}$ & $\underline{365}$ & 1122 & 1816 \\
\hline & & $\overline{5469}$ & $\overline{657}$ & 2019 & 3268 \\
\hline \multirow{4}{*}{$\mathrm{CoSO}_{4} 0,1 \%$} & \multirow{2}{*}{-} & $\underline{1895}$ & $\underline{372}$ & $\underline{1580}$ & $\underline{1315}$ \\
\hline & & 3314 & 364 & 1545 & 2216 \\
\hline & \multirow{2}{*}{+} & $\underline{2723}$ & $\underline{259}$ & $\underline{962}$ & $\underline{1598}$ \\
\hline & & $\overline{5214}$ & $\overline{496}$ & $\overline{1842}$ & $\overline{3257}$ \\
\hline \multirow[t]{4}{*}{$\mathrm{H}_{3} \mathrm{BO}_{3} 0,1 \%$} & \multirow{2}{*}{-} & $\underline{2292}$ & $\underline{499}$ & $\underline{1640}$ & $\underline{1567}$ \\
\hline & & $\overline{3408}$ & $\overline{541}$ & $\overline{1777}$ & 2460 \\
\hline & \multirow[b]{2}{*}{+} & $\underline{3983}$ & $\underline{361}$ & $\underline{1115}$ & $\underline{2285}$ \\
\hline & & $\overline{5358}$ & $\overline{649}$ & 2002 & 4206 \\
\hline \multirow[t]{4}{*}{ Феровит $0,2 \%$} & \multirow{2}{*}{-} & $\underline{1891}$ & 372 & 1452 & 1294 \\
\hline & & $\overline{2103}$ & $\overline{342}$ & $\overline{1519}$ & $\overline{2100}$ \\
\hline & \multirow{2}{*}{+} & $\underline{1940}$ & $\underline{199}$ & $\underline{976}$ & $\underline{1306}$ \\
\hline & & $\overline{4192}$ & $\overline{442}$ & $\overline{1676}$ & 3262 \\
\hline \multirow[t]{4}{*}{ Силиплант $0,2 \%$} & \multirow{3}{*}{-} & $\underline{2658}$ & $\underline{464}$ & $\underline{1861}$ & $\underline{1770}$ \\
\hline & & 2794 & 549 & 2203 & 2420 \\
\hline & & $\underline{4599}$ & $\underline{347}$ & $\underline{1365}$ & $\underline{2627}$ \\
\hline & + & $\overline{5799}$ & $\overline{559}$ & $\overline{3200}$ & $\overline{3576}$ \\
\hline $\mathrm{HCP}_{05}{ }^{\mathrm{A}}$ & & $\underline{106 / 149}$ & $\underline{40 / 30}$ & $\underline{62 / 88}$ & $\underline{42 / 26}$ \\
\hline $\mathrm{HCP}_{05}$ В и $\mathrm{AB}$ & & $\overline{121 / 52}$ & $\overline{49 / 30}$ & $\overline{46 / 90}$ & $\overline{57 / 56}$ \\
\hline
\end{tabular}

Примечание: в числителе содержание нитратов в сырье растений 2 г. в., в знаменателе - 3 г. в. Фактор А - некорневая подкормка, фактор В - элементы структуры травы, AB - взаимодействие факторов. 
Некорневые подкормки растений 2 г. в. растворами феровита и $\mathrm{CoSO}_{4}$ позволили несколько снизить накопление нитратов в соке по сравнению с контролем (на 8 и 4 \% соответственно). Те же варианты опыта, но на фоне внесения азота давали более значительное снижение уровня нитратов - на 20 и 6\%. Аналогичная закономерность прослеживалась для сока травы растений 3 г. в. Подкормки растворами соединений, содержащих микроэлементы, снижали концентрацию нитратов в соке на 14-17\% к контролю. В случае же комплексных некорневых подкормок растений 3 г. в. растворами карбамида и соединений железа и кобальта содержание нитратов практически не менялось, тогда как в других вариантах оно возрастало на 13-34\%.

В итоге, мы констатируем снижение уровня нитратов в траве свежей, ее структурных элементах и соке независимо от возраста растений эхинацеи, а также наличия или отсутствия подкормки раствором карбамида при некорневой подкормке соединениями железа и кобальта. Ион железа присутствует в нитритредуктазе, катализирующей восстановление нитратов до нитритов. Железо и кобальт входят в состав нитрилгидратаз, катализирующих реакцию образования амида из нитрилов, которые являются предшественниками нитратов. Нитрилгидратазы - это металлоферменты, имеющие в своем активном центре негемовое железо или кобальт и распределенные на две группы - железосодержащие (Fe-тип) и кобальтсодержащие (Со-тип) [17].

Вегетационный сезон 2010 г. характеризовался экстремально жаркими и засушливыми погодными условиями, что отразилось на концентрации нитратов в сырье (табл. 2). Накопление нитратов в траве эхинацеи 3 г. в. в целом было несколько выше по сравнению травой, полученной от растений того же возраста в 2009 г. В листьях превышение составило 17\%, в стеблях, как и в траве, - 3\%, соцветия и их зачатки содержали одинаковое количество нитратов независимо от года проведения опыта. В итоге, целевой продукт (сок) накапливал на 6\% больше нитратов по сравнению с соком травы растений 3 г. в. в 2009 г. В 2010 г. по сравнению с 2009 г. отмечено достоверное увеличение содержания нитратов в сырье эхинацеи пурпурной, полученном от одних и тех же растений (в 2009 г. растения 2 и 3 гг. в., 2010 г. они же 3 и 4 гг. в. соответственно). В структурных элементах травы и в самой траве эхинацеи концентрация нитратов возрастала с увеличением возраста на 3-73\%. Сок, выделенный из травы растений 3 г. в., в 2010 г. содержал почти вдвое больше нитратов, чем сок из травы 2 г. в. в 2009 г. В этом случае сказалось влияние как погодных условий 2010 г., так и возраста растений.

В 2010 г. с увеличением возраста растений, с которых срезали траву свежую, возрастало и содержание нитратов в сырье и соке. При этом у растений 7 г. вегетации в 2010 г. наблюдалась наибольшая достоверная концентрация нитратов в стеблях (в 1,3 раза выше, чем в среднем в стеблях растений других возрастов в 2010 г.) и наименьшая - в листьях.

Такое распределение нитратов по структуре травы свидетельствует о том, что к 7 г. в. у растений эхинацеи понижается облиственность. Как следствие высокого содержания нитратов в стеблях, трава, срезанная с растений 7 г. в., а также полученный из нее сок содержали максимальное количество нитратов по сравнению с травой, полученной от растений 3, 4 и 5 гг. вегетации.

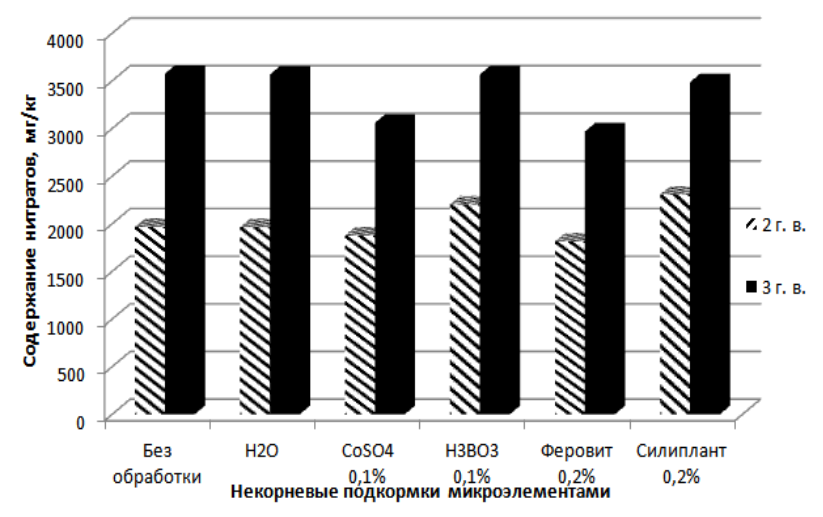

Рис. 1. Содержание нитратов (мг/кг) в соке из травы эхинацеи пурпурной свежей в зависимости от некорневых подкормок растений 2 и 3 гг. в. микроэлементами

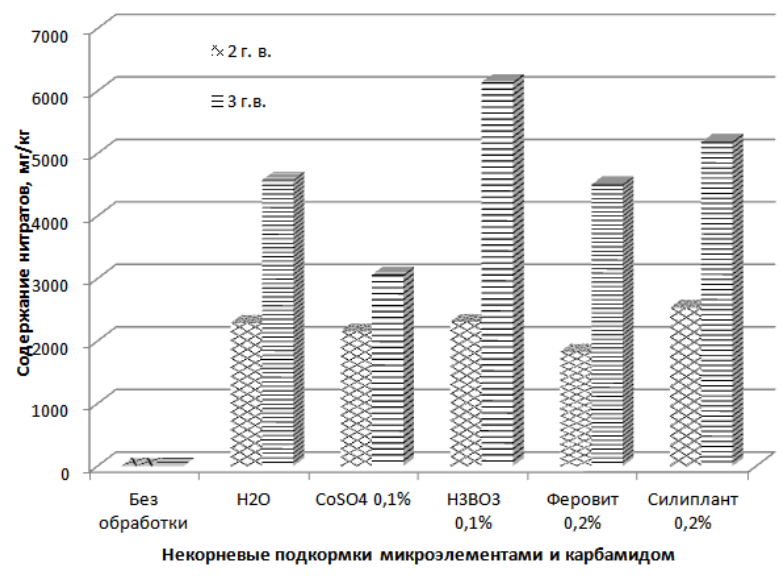

Рис. 2 Содержание нитратов (мг/кг) в соке из травы эхинацеи пурпурной свежей в зависимости от некорневых подкормок растений 2 и 3 гг. в. микроэлементами и азотом 
Таблица 2. Содержание нитратов в свежем сырье и соке эхинацеи пурпурной разных возрастов 2010 г., мг/кг

\begin{tabular}{c|c|c|c|c}
\hline Показатель & 3-й год вегетации & 4-й год вегетации & 5-й год вегетации & 7-й год вегетации \\
\hline Листья & 642 & 668 & 626 & 474 \\
Соцветия и их зачатки & 1804 & 1836 & 1852 & 1828 \\
Стебли & 3510 & 3841 & 3630 & 4570 \\
Трава & 1509 & 1651 & 1561 & 4965 \\
Сок & 3800 & 4140 & 4200 & $\underline{54}$ \\
$\mathrm{HCP}_{05}{ }^{\mathrm{A}}$ & $\underline{48}$ & $\underline{56}$ & $\underline{56}$ & $\underline{52}$
\end{tabular}

Примечание: фактор А - возраст производящих растений, фактор В - элементы структуры травы, АВ - взаимодействие факторов.

\section{Bblводы}

1. Некорневая подкормка растений эхинацеи растворами феровита и $\mathrm{CoSO}_{4}$ в фазу бутонизации способствовала снижению уровня нитратов в траве свежей, ее структурных элементах и соке независимо от возраста растений, а также наличия подкормки раствором карбамида, что связано с присутствием ионов железа и кобальта в активных центрах некоторых ферментов азотного обмена.

2. С увеличением возраста растений трава эхинацеи свежая, ее структурные элементы и сок содержат большее количество нитратов независимо от наличия или отсутствия некорневой подкормки растворами микроэлементов и карбамида.

3. Поскольку стебли эхинацеи пурпурной имеют стабильно высокую концентрацию нитратов, траву на сок следует убирать на высокой срезке.

4. Содержание нитратов в соке травы эхинацеи пурпурной свежей достоверно выше, чем в траве. Повышение концентрации нитратов в соке по сравнению с их содержанием в траве составило независимо от вариантов для растений 2 г. в. 35-43\%, а для растений 3 г. в. 38-46\%.

\section{Сиисок литературы}

1. ТУ 9373-142-04868244-2008. Эхинацеи пурпурной трава свежая. М., 2008.

2. Кудеяров В.Н., Башкин В.Н., Кудеярова А.Ю., Бочкарев А.Н. Экологические проблемы применения минеральных удобрений. М., 1984. 212 с.

3. Токсикологическая химия. Метаболизм и анализ токсикантов : учебное пособие / под ред. Н.И. Калетиной. M., 2008. $1016 \mathrm{c}$.

4. Пронина Н.Б. Экологические стрессы. М., 2001. 312 с.

5. Опополь Н.И. Гигиеническая значимость нитратного загрязнения объектов окружающей среды // Экологические проблемы накопления нитратов в окружающей среде. Пущино, 1989. С. 131.

6. Ильницкий А.П. Нитраты как средовой фактор, оказывающий влияние на здоровье населения // Экологические проблемы накопления нитратов в окружающей среде. Пущино, 1989. С. 130.

7. Дмитриев С.В. Изучение влияния некоторых антропогенных факторов на качество сырья дикорастущих лекарственных растений : автореф. дис. ... канд. фарм. наук. М., 1991.

8. Тома С.И. Микроэлементы - важный экзогенный фактор управления формированием продуктивности и устойчивости растений // Физиолого-биохимическая роль микроэлементов в управлении адаптивными реакциями и продуктивностью растений. Кишинев, 1990. С. 3-9.

9. Ягодин Б.А., Жуков Ю.П., Кобзаренко В.И. Агрохимия М., 2002. 584 с.

10. Ягодин Б.А., Ступакова Г.А. Физиологическая роль кобальта и факторы, влияющие на его поступление в растения // Агрохимия. 1989. Т. 12. С. 111-120.

11. Пушкина Г.П., Бушковская Л.М., Климахин Г.И. Эффективность применения микроудобрения феровит на лекарственных культурах // Новые и нетрадиционные растения и перспективы их использования: VII Международный симпозиум. Пущино, 2007. Т. 2. С. 287-290.

12. ГОСТ 29279-95. Продукты переработки плодов и овощей. Методы определения нитратов. М., 2010. 15 с.

13. Доспехов Б.А. Методика полевого опыта. М., 1985.351 с.

14. Бабаева Е.Ю., Загуменников В.Б., Волобуева В.Ф. Изменение содержания фенольных соединений в сырье эхинацеи пурпурной при использовании комплексных микроэлементных препаратов // VII Международный симпозиум по фенольным соединениям: фундаментальные и прикладные аспекты. М., 2009. С. 22-24.

15. Майсурадзе Н.И., Киселев В.П., Черкасов О.А. и др. Методика исследований при интродукции лекарственных растений // Обзорная информация ВИЛР. М., 1984. 32 с.

16. Соколов О.А., Семенов В.М., Агаев В.А. Нитраты в окружающей среде. Пущино, 1988. 316 с.

17. Дебабов В.Г., Яненко А.С. Биокаталитический гидролиз нитрилов // Обзорный журнал по химии. 2011. Т. 1, №4. C. 376-394. 
Zagumennicov V.B. ${ }^{l}$, Molchanova A.V. ${ }^{2}$, Babaeva E.Y. ${ }^{3 *}$, Petrova A.L. ${ }^{3}$ TO THE QUESTION OF ACCUMULATION OF NITRATES IN ECHINACEA PURPUREA FRESH GRASS AND ITS JUICE AT AMENDMENT MACRO AND MICROELEMENTS

${ }^{1}$ All-Russian Research Institute of Medicinal and Aromatic Plants RAAS, Grina st., 7, Moscow, 117216 (Russia)

${ }^{2}$ All-Russian Research Institute of breeding and seed vegetable crops, Forest Town Odintsovo district, Moscow region, 143080, (Russia),e-mail:vovka_ks@rambler.ru

${ }^{3}$ Peoples' Friendship University of Russia, st. Miklukho-Maklaia, 6, Moscow, 117198 e-mail: babaevaelena@mail.ru

For the first time the content of nitrates in Echinacea purpurea fresh grass, its structural elements and the juice of two years of research were analyzed. Analysis was based on the age of plants, foliar fertilizing solutions containing N, Co, Fe, B, Si, and years of experience.

Keywords: Echinacea purpurea L.(Moench), fresh grass, juice, nitrates, macro - and microelements.

\section{References}

1. TU 9373-142-04868244-2008. Ekhinatsei purpurnoi trava svezhaia. [Specifications 9373-142-04868244-2008 Echinacea purpurea herb fresh]. Moscow, 2008. (in Russ.).

2. Kudeiarov V.N., Bashkin V.N., Kudeiarova A.Iu., Bochkarev A.N. Ekologicheskie problemy primeneniia mineral'nykh udobrenii. [Ecological problems of fertilizer application]. Moscow, 1984, 212 p. (in Russ.).

3. Toksikologicheskaia khimiia. Metabolizm i analiz toksikantov: uchebnoe posobie. [Toxicological Chemistry. Metabolism and analysis of toxicants: a tutorial.]. Ed. N.I. Kaletina. Moscow, 2008, 1016 p. (in Russ.).

4. Pronina N.B. Ekologicheskie stressy. [Environmental stresses.]. Moscow, 2001, 312 p. (in Russ.).

5. Opopol' N.I. Ekologicheskie problemy nakopleniia nitratov v okruzhaiushchei srede. [Ecological problems of nitrate accumulation in the environment.]. Pushchino, 1989, p. 131. (in Russ.).

6. II'nitskii A.P. Ekologicheskie problemy nakopleniia nitratov v okruzhaiushchei srede. [Ecological problems of nitrate accumulation in the environment.]. Pushchino, 1989, p. 130. (in Russ.).

7. Dmitriev S.V. Izuchenie vliianiia nekotorykh antropogennykh faktorov na kachestvo syr'ia dikorastushchikh lekarstvennykh rastenii : avtoref. dis. ... kand. farm. nauk. [Study of the influence of anthropogenic factors on some quality raw wild medicinal plants: Summary the dissertation of pharmaceutical sciences.]. Moscow, 1991. (in Russ.).

8. Toma S.I. Fiziologo-biokhimicheskaia rol' mikroelementov v upravlenii adaptivnymi reaktsiiami i produktivnost'iu rastenii. [Physiological and biochemical role of trace elements in the management of adaptive responses and plant productivity.]. Kishinev, 1990, pp. 3-9. (in Russ.).

9. Iagodin B.A., Zhukov Iu.P., Kobzarenko V.I. Agrokhimiia. [Agrochemistry]. Moscow, 2002, 584 p. (in Russ.).

10. Iagodin B.A., Stupakova G.A. Agrokhimiia, 1989, vol. 12, pp. 111-120. (in Russ.).

11. Pushkina G.P., Bushkovskaia L.M., Klimakhin G.I. Novye i netraditsionnye rasteniia i perspektivy ikh ispol'zovaniia: VII Mezhdunarodnyi simpozium. [Новые и нетрадиционные растения и перспективы их использования: VII Международный симпозиум]. Pushchino, 2007, vol. 2, pp. 287-290. (in Russ.).

12. GOST 29279-95. Produkty pererabotki plodov i ovoshchei. Metody opredeleniia nitratov. [State Standard 29279-95. Products of fruits and vegetables. Methods for determination of nitrates.]. Moscow, 2010, 15 p. (in Russ.).

13. Dospekhov B.A. Metodika polevogo opyta. [Technique of field experience]. Moscow, 1985, 351 p. (in Russ.).

14. Babaeva E.Iu., Zagumennikov V. B., Volobueva V.F. VII Mezhdunarodnyi simpozium po fenol'nym soedineniiam: fundamental'nye i prikladnye aspekty. [VII International Symposium on phenolic compounds: fundamental and applied aspects.]. Moscow, 2009, pp. 22-24. (in Russ.).

15. Maisuradze N.I., Kiselev V.P., Cherkasov O.A. Obzornaia informatsiia VILR. [Overview of the All-Union Institute of Medicinal Plants]. Moscow, 1984, 32 p. (in Russ.).

16. Sokolov O.A., Semenov V.M., Agaev V.A. Nitraty $v$ okruzhaiushchei srede. [Nitrates in the environment.]. Pushchino, 1988, 316 p. (in Russ.).

17. Debabov V.G., Ianenko A.S. Obzornyi zhurnal po khimii, 2011, vol. 1, no. 4, pp. 376-394. (in Russ.).

Received January 27, 2013

\footnotetext{
* Corresponding author.
} 
